\title{
EDUCAÇÃO ESCOLAR E INTERCULTURALIDADE: A INSERÇÃO DO ALUNO INDÍGENA NO CONTEXTO URBANO EM BOA VISTA - RR
}

\author{
Claudina Miranda e Silva ${ }^{(*)}$ \\ Selma Maria Cunha Portela ${ }^{(*)}$ \\ Maristela Bortolon de Matos $^{(* *)}$
}

A década de 70 marca o início da organização do movimento indígena no Brasil, apoiado por diversos parceiros como a igreja, universidades e ONG'S, em acordo com outros movimentos indígenas internacionais. A partir daí a Fundação Nacional do Índio (FUNAI) faz parceria com o Summer Institute of Linguistics (SIL) dos EUA, surge então uma perspectiva intercultural dentro desta parceria e promoveu-se a oficialização do ensino bilíngue nas escolas em terras indígenas. Ainda no final dos anos 70 discussões apresentadas durante a realização do Conselho Indigenista Missionário (CIMI) em Mato Grosso foi questionada a diferença entre educação escolar indígena e educação para o índio, buscando compreender se havia de fato necessidade ou não de alfabetização na língua materna e a reflexão acerca de um modelo de ensino alternativo (Documento Base/II CONEEI, 2016).

No início dos anos 80, as lutas, os encontros e os debates realizados ganham espaço, organizam-se os movimentos indígenas e a sociedade civil em busca da redemocratização do Brasil e a garantia do reconhecimento dos direitos indígenas na Constituição Federal. Uma vez que o direito à Educação Escolar Indígena era diferenciado, pois além do reconhecimento aos direitos, era necessário o reconhecimento da multiculturalidade e das relações interculturais, apresentando uma proposta de inclusão das minorias étnicas.

Em 1988, com promulgação da Constituição Federal, fato que marca a redefinição das relações entre o estado brasileiro e as sociedades indígenas, o direito a uma educação escolar específica e diferenciada é garantido e “os povos indígenas assumem o debate sobre a

\footnotetext{
${ }^{(*)}$ Mestranda em Educação pela Universidade Estadual de Roraima - UERR, em parceria com o Instituto Federal de Educação, Ciência e Tecnologia de Roraima - IFRR. Professora de Ensino Básico, Técnico e Tecnológico EBTT/IFRR. E-mail: mirandaclaudina@gmail.com.

${ }^{(* *)}$ Mestranda em Educação pela Universidade Estadual de Roraima - UERR, em parceria com o Instituto Federal de Educação, Ciência e Tecnologia de Roraima - IFRR. Professora de Ensino Fundamental I da Rede Estadual de Boa Vista - RR, experiência em Educação com ênfase na modalidade de Educação Especial e Inclusiva. E-mail: portelagil@gmail.com.

${ }^{(* * *)}$ Doutora em Educação pela UNISINOS. Professora Titular do Instituto Federal de Educação, Ciência e Tecnologia de Roraima - IFRR. Docente do Mestrado em Educação da UERR/IFRR. E-mail: maristela@ifrr.edu.br.
} 
implementação da Política de Educação Escolar Indígena e exigem sua efetivação e o respeito às diferenças e especificidades de cada povo indígena”. (Documento Base/II CONEEI,2016, p.18).

Em um contexto dos movimentos sociais e educacionais que visam o convívio democrático e a construção de referências que compreenda de fato o fenômeno das relações interculturais, fundamenta-se num processo recíproco em busca de respeito, valorização à diferença da pluralidade social e cultural em Roraima. A pesquisa contempla a interculturalidade a partir de uma concepção de apreço à diversidade e o reconhecimento desta dentro da escola, partindo do princípio de inserção do aluno indígena em um espaço escolar urbanizado.

Visando uma contextualização acerca da instituição pesquisada, cabe destacar que a mesma está situada na zona periférica de Boa Vista/RR, no Bairro São Bento (Brigadeiro) e atende todo o entorno da região contemplando os seguintes bairros: Raiar do Sol, Araceli, Operário, Bela Vista e Nova Vida.

\section{LDB 9.394/96 E A EDUCAÇÃO INTERCULTURAL}

Fundamentada na Lei de Bases e Diretrizes da Educação Básica de 1996, a natureza da educação indígena foi transformada, propondo a valorização e o reconhecimento da educação intercultural, assegurando o que já havia garantido a Constituição Federal de 1988.

O artigo 78 da LDB garante o desenvolvimento de programas integrados de ensino e pesquisa, para oferta de educação escolar bilíngue e intercultural aos povos indígenas e propõe dois objetivos que compreende a inserção do aluno indígena à escola:

1) proporcionar aos índios, suas comunidades e povos, a recuperação de suas memórias históricas, a reafirmação de suas identidades étnicas, a valorização de suas línguas e ciências;

2) garantir aos índios, suas comunidades e povos, o acesso às informações, conhecimentos técnicos e científicos da sociedade nacional e demais sociedades indígenas e não índias. (LDB 9.394/96).

As discussões apresentadas na II- CONEEI/RR (Conferência Nacional de Educação Escolar Indígena) e os relatos dos professores indígenas nos GT’S apresentou a necessidade de construção do currículo próximo à realidade da comunidade, que resgate e valorize os costumes, as memórias históricas, a reafirmação das identidades étnicas, sobretudo o respeito as suas línguas e especificidade de cada povo indígena. 
Com a apresentação da educação intercultural, comunitária e diferenciada já garantida na LDB, criou-se o Referencial Curricular para Escolas Indígenas (RCNEI, 1998), um documento que transformou a concepção de políticas públicas voltadas para a educação intercultural indígena, do ponto de vista de sua efetividade. A partir disso teríamos um olhar para a diversidade como um conjunto de recursos para estruturar as relações interculturais e não como um problema ou conflito histórico.

Para compreendermos o processo de construção da educação escolar indígena, é necessário reconhecermos a educação enquanto objeto de inserção do ponto de vista histórico, cultural, social e econômico. Primeiro consideramos que a partir da elaboração do RCNE/indígena/98, pensou-se efetivamente em programas que atendesse aos anseios e interesses das comunidades indígenas, embora os movimentos das décadas de 70 e 80 tenham efetivado conquistas importantes.

Com os avanços no que diz respeito à legislação, os estados e municípios apresentam sistemas educacionais que consideram a diversidade cultural e étnica dos povos indígenas, neste contexto a percepção de currículo é mais próxima de suas realidades. Entendemos que o Referencial Curricular oferece subsídio para o enfrentamento de grandes desafios que os povos indígenas possuem na atualidade, ele posiciona o espaço escolar como local de currículo e define as características da escola indígena:comunitária (de acordo com as concepções, projetos e princípios indígenas); intercultural (reconhecer e manter a diversidade cultural e linguística); bilíngue/multilíngue, específica e diferenciada (aspirações particulares do povo indígena).

Dessa forma é imprescindível reconhecer os processos específicos de aprendizagem, a forma como os povos indígenas se organizam e se constituem, visando práticas educacionais adequadas às diversidades culturais que se manifestam na comunidade, desse modo é possível associar a escola com a vida comunitária.

\section{EDUCAÇÃO E INTERCULTURALIDADE EM RORAIMA}

O estado de Roraima é representado pela diversidade cultural presente em cada município, uma vez que dentro da sua formação histórica caracteriza-se pela miscigenação dos povos que constituem a nação brasileira: o índio, o europeu e o negro, formando, assim, os mestiços da região - caboclos.

Segundo o IBGE2010, mais tarde, com a chegada dos migrantes, especialmente nordestinos, formou-se uma mistura de cultura singular, que caracteriza grande parte da população,sua identidade coletiva, suas culturas, suas memórias históricas, seus valores e modo de vida. Ainda no 
que se refere à população, Roraima é o estado brasileiro com o maior número de indígenas vivendo em terras demarcadas no país, mais de 49 mil autodeclarados, segundo o censo 2010 estão distribuídos em 09 etnias: Macuxi, Yanomami, Ingarikó, Taurepang, Wai-wai, Wapixana, Yekuana, Pantamona, Waimiri- atroari.

Com base na característica intercultural que o estado se constitui, é comum encontrarmos em escolas da capital uma diversidade étnica evidente, reúne- se no contexto urbano: indígenas, venezuelanos e migrantes de outras regiões do Brasil. É com base nessas diferenças culturais que vivemos um histórico conflito de negação x afirmação da identidade, trata-se de um contexto onde, segundo relatos, os indígenas se percebem marginalizados, pressionados a negação da sua identidade, ou seja, não se sentem a vontade dentro dessa estrutura urbana. Dado isso, atentamos a concepção de Oliveira (2005, p. 28).

Em suma, se o preconceito sempre mostrou ser uma barreira ao pleno reconhecimento de identidades étnicas, seja como autorreconhecimento, seja reconhecimento pelos outros, no que esse estado de coisas poderia afetar alguém, nas mesmas circunstâncias, em sua luta pela cidadania? Sob o manto protetor das políticas de Estado (no caso, as políticas indigenistas), não haveria uma demanda de caráter moral ou ético a orientar a formulação dessas políticas públicas.

A luta desenvolvida nos movimentos sociais promoveu um amadurecimento acerca das diferenças culturais, trata-se de uma conquista recente, mas segundo Fleuri “o problema do encontro e do conflito entre culturas é antigo” (2003, p. 18), muitas vezes sendo enfrentado dentro de um processo de descaracterização da própria cultura, sobre uma perspectiva etnocêntrica de imposição, opressão e desconstrução, que historicamente se fundiu dentro das instituições de ensino. “A própria educação em particular a escola, tem desempenhado o papel de agenciar a relação entre culturas com poder desigual”. (FLEURI, 2003, p. 18), ou seja, numa tentativa equivocada de hierarquizar as diferentes culturas.

Partindo deste princípio, a perspectiva de educação intercultural reconhece a necessidade de promover uma integração entre as culturas, à superação do conflito das diferenças, ainda que numa tentativa de eximir a escola do papel exercido durantes séculos de proclamar a inferioridade cultural em busca da homogeneização da língua e da cultura. Diante dissona busca incansável de se promover uma educação culturalmente democrática, o autor destaca.

A educação passa a ser entendida como processo construído pela relação tensa e intensa entre diferentes sujeitos, criando contextos interativos que, justamente por se conectar dinamicamente com os diferentes contextos culturais em relação aos quais os 
diferentes sujeitos desenvolvem suas respectivas identidades, torna-se um ambiente criativo e propriamente formativo, ou seja, estruturante de movimentos de identificação subjetivos e socioculturais (FLEURI, 2003, p. 32)

Desse modo é relevante destacar o contexto de inserção do aluno indígena na escola urbana.Para isto surge a discussão seguinte com intuito de propagar-se a reflexão sobre tal realidade.

\section{A INSERÇÃO DO ALUNO INDÍGENA NA ESCOLA URBANA}

A escola urbana em Boa Vista - RR atende o aluno indígena e não indígena, mas a mesma não está preparada como aponta as discussões do documento final da I CONEEI/2009 para compreender e reconhecer o processo intercultural que a constitui enquanto instituição de ensino. Não basta a inserção, o espaço escolar que abriga as diferenças étnicas clama por uma proposta de inclusão junto às políticas públicas afirmativas, estas propõem igualdade de oportunidades e convivência democrática entre diferentes grupos e culturas. Apesar deste contraste, Fleuri (2003) aponta que as culturas não são extintas, apenas sofrem um processo de transfiguração afirmando que "Este processo de tentativa de extinguir as culturas não foi possível, pois apesar de serem negadas aparentemente, estas culturas não desapareceram, apenas houve uma transformação em desigualdades sociais ou em processo de marginalização” (p. 19).

Se considerarmos o processo de marginalização como aquele que tende a excluir não só educandos indígenas, mas outros que façam parte das ditas “minorias" como negros, deficientes,quilombolas, ribeirinhos etc., então se constata que as relações interculturais estão ausentes do espaço escolar. E isto implica dizer também que as Instituições não estão cumprindo as determinações legais, ignoram a lei e as discussões sobre interculturalidade se pautam no campo apenas teórico. Principalmente em se tratando da Instituição escola, pois inúmeras são aquelas que contemplam em seu Projeto Político Pedagógico a dimensão intercultural, no entanto, na prática pedagógica e social escolar não é colocado em prática. Isso não só é grave como negligencia o direito à convivência e valorização intercultural efetiva num espaço em que deveria promover essa prática servindo de exemplo para outros espaços da sociedade.

Destacamos essa convivência intercultural como uma prática inclusiva, quando o educando deixa de ser apenas inserido e passa se relacionar no espaço como um sujeito culturalmente capaz de aprender e ensinar a partir de sua vivência, que traz consigo uma memória cultural e esta por sua vez pode ser aproveitada como subsídio pedagógico. 
Segundo Sassaki (2006):

É substancialmente relevante que denominemos o conceito de sociedade inclusivista, a qual tem o objetivo de que possamos ser participantes ativos na construção de uma sociedade que realmente seja para todas as pessoas independentemente de sua cor, idade, gênero, tipo de necessidade especial e qualquer outro atributo pessoal. Estas são chamadas inclusivistas por que abrangem valores que defendem a inclusão (p. 27).

Seguindo esse pensamento, propomo-nos refletir sobre como se constitui a inclusão social, uma vez que esta deve alcançar todas as esferas sociais. Sassaki (1997, p. 3) defende "como um processo bilateral no qual as pessoas, ainda excluídas, e a sociedade buscam em parceria equacionar, decidir sobre soluções e efetivar a equiparação de oportunidades para todos”.

A partir de tal esclarecimento sobre constituição da inclusão social, subentende que nenhuma deve ser excluída, e nesse processo de construção social o aluno indígena é peça fundamental,não porque seja mais importante que os outros educandos, mas considerando a realidade local. Ele necessita de um olhar pedagógico que favoreça a relação intercultural, e desta seja extraído frutos para a efetivação de uma educação universal defendida pela Constituição Federal.

\section{PERCURSO METODOLÓGICO}

Severino (2007), afirma que “a ciência se constitui aplicando técnicas, seguindo um método e apoiando-se em fundamentos epistemológicos, tendo elementos gerais que são comuns a todos os processos de conhecimento que pretendem realizar, marcando toda atividade de pesquisa” (p. 117).

Assim a presente pesquisa percorreu o caminho metodológico concentrando-se no estudo de caso de uma Escola Municipal localizada no Bairro São Bento, pertencente à zona periférica do Município de Boa Vista estado de Roraima. Sendo esta escola a que possui o maior número de alunos regularmente matriculados, alunos identificados como indígenas, sendo no total de 31 alunos distribuídos nos anos iniciais do Ensino Fundamental I.

Foi realizado um estudo de caso, embasado em uma pesquisa bibliográfica e análise documental. Também foi realizada uma entrevista não diretiva, com três Coordenadores Pedagógicos da escola e a três Professores de diferentes turmas. A pesquisa em questão foi de abordagem qualitativa.

O método compreendido como estudo de caso, pode ter várias interpretações quanto a sua aplicação, ao que Yin propõe para o método. 
[...] uma investigação científica que investiga um fenômeno contemporâneo dentro de seu contexto da vida real, especialmente quando os limites entre o fenômeno e o contexto não estão claramente definidos; enfrenta uma situação tecnicamente única em que haverá muito mais variáveis de interesse do que pontos de dados e, como resultado, baseia-se em várias fontes de evidência [...] e beneficia-se do desenvolvimento prévio de proposições teóricas para conduzir a coleta e análise dos dados (YIN, 2001, p. 32-33).

Neste contexto, o estudo de caso é visto como beneficiador das proposições teóricas que conduzem as outras etapas da pesquisa como esta que optou-se por pesquisa bibliográfica, definida por Severino (2007) como aquela que realiza a partir do registro disponível, decorrentes de pesquisas anteriores, em documentos impressos, como livros, artigos, teses etc. utiliza-se de dados ou de categorias teóricas já trabalhados por outros pesquisadores e devidamente registrados. O mesmo autor trata a pesquisa documental “como fonte documentos no sentido amplo, ou seja, não só documentos impressos, mas, sobretudo outros tipos de documentos, tais como jornais, fotos, filmes etc.” (2007, p. 122).

Sabe-se que todo o processo de pesquisa é importante e deste faz parte às técnicas de pesquisa, que segundo Severino (2007) são os procedimentos operacionais que servem de mediação prática para a realização das pesquisas. Assim como as entrevistas são consideradas técnica de coletas de informações sobre um determinado assunto, diretamente solicitadas aos sujeitos pesquisados.

A técnica escolhida para atividade foi às entrevistas não diretivas, por meio delas, colhem-se informações dos sujeitos a partir do seu discurso livre. “O entrevistador deve praticar um diálogo descontraído, deixando o informante à vontade para expressar sem constrangimentos suas representações” (SEVERINO, 2007, p. 125).

\section{RESULTADOS E DISCUSSÕES}

Nesta parte do estudo apresentamos uma análise comparativa entre as informações prestadas pelos 03 professores e 03 coordenadores pedagógicos entrevistados acerca da inserção do aluno indígena no contexto urbano e como a educação escolar é construída em um contexto intercultural.

Segundo a concepção dos gestores pedagógicos entrevistados, a escola como um todo precisa estar preparada para receber o aluno indígena, uma vez que a interação a partir da língua ocorreria significantemente, todavia para que o aluno possa interagir é necessário que a escola se 
constitua de características específicas; e atenda a diversidade cultural e linguística, que seja bilíngue/multilíngue. Cabe ressaltar que dentro da instituição, ainda que esta não seja indígena, as relações interculturais existem e são frutos do encontro dos diversos povos, seus costumes, hábitos, crenças e valores.

Dentro deste contexto o ambiente de ensino compreende a necessidade de interação e omite o processo de exclusão, pois à medida que o aluno indígena é inserido na escola urbana, para que o mesmo participe da “interação" é pressionado a aprender a língua portuguesa e consequentemente a negar ou esquecer a língua materna, então percebemos a escola enquanto espaço de propagação da monocultura.

A escola, espaço histórico de imposição de valores e assimilação para incorporação à economia de mercado e, nesse processo, devoradora de identidades, passa a ser reivindicada pelas comunidades indígenas como espaço de construção de relações intersocietárias baseadas na interculturalidade e na autonomia política (MEC, 2007, p. 09).

Por outro lado, sabemos que a desconstrução da identidade cultural faz parte de uma história nefasta, que foi construída desde a educação jesuítica no Brasil colônia aos dias atuais, onde a fé, sobretudo a língua eram objetos de imposição cultural.

Compreende-se que a concepção de educação intercultural e a inserção do aluno indígena é algo distante de ser concebida no ambiente escolar, para os coordenadores a entrada dos alunos seria o mais natural possível, mas a princípio a língua representa um verdadeiro desafio. Tal situação nos faz perceber que a diversidade étnica encontra-se em situação de exclusão, e isto é evidente quando encontramos em uma sala de aula índios, não índios e venezuelanos. Constatou-se que não temos uma escola bilíngue, logo não temos efetivamente uma educação intercultural. A interculturalidade existe, enquanto resultado das relações diárias, contudo não há respeito ou um reconhecimento às diferenças culturais. Para Candau (2003, p. 4), os grupos sociais reconhecerem as diferenças e as relações culturais existentes nos diversos grupos.

Quanto ao nível social, a interculturalidade orienta processos que têm por base o reconhecimento do direito à diversidade e a luta contra todas as formas de discriminação e desigualdade social e tentam promover relações dialógicas e igualitárias entre pessoas e grupos que pertencem a universos culturais diferentes.

Quanto à organização pedagógica da escola contamos com a presença de três representantes que atuam nos três turnos de funcionamento da instituição. Não há equipe multidisciplinar, ou seja, quando há problemas sociais, psicológicos, assistenciais e indisciplina, convida-se a família para 
uma orientação junto à coordenação pedagógica. A referência para todas as situações descritas acima fica na função do Coordenador Pedagógico.

Dentro deste contexto evidenciamos que o Projeto Político Pedagógico da escola está em processo de reformulação, mesmo já apresentando um tópico que trata da educação intercultural, compreendeu-se com base nos relatos que a diversidade cultural ainda faz parte de raros momentos de discussão e superficialmente apresentada nos encontros pedagógicos, na Semana da Consciência Negra, no Dia do índio entre outros eventos.

Baseado nas informações de um dos docentes, os debates sobre as relações interculturais no contexto escolar são inexpressivos diante da realidade plural que a escola abriga. Primeiro atentamos para um contexto multilíngue, interétnico e diversificado a partir do encontro dos diversos povos. E é diante deste cenário que construímos um espaço carregado de preconceitos, de exclusão e marginalização das classes sociais.

Seguindo a compreensão do docente não havia um entendimento por parte da escola sobre o que é ser indígena na atualidade, a partir daí observou-se que alguns alunos não se percebiam indígenas, portanto, não se consideram ou não se reconhecem enquanto indígena. Tal situação é justificada para o entrevistado quando muitas vezes em comemorações diversas, visualizamos a imagem alegórica do índio, descartando ou negligenciando a sua existência enquanto ser humano normal que possui origem, família, identidade, cultura específica, rica e diversificada.

No decorrer da sua prática o professor identificou que com o número de alunos indígenas matriculados regularmente, a educação escolar em sua efetividade não reconhece e não dissemina as diferenças culturais, justificando a dificuldade de interação dos alunos indígenas como objeto de isenção da responsabilidade social e cultural que a escola possui. Fazendo com que o aluno sinta-se excluído e negue a sua cultura, seus costumes, os valores e a sua identidade.

A identidade que se manifesta sem solidez, precisa ser reafirmada, tanto pela escola quanto pelo próprio aluno, em conformidade com esse pensamento afirma Bauman (2005, p. 17):

Tornamo-nos conscientes de que o "pertencimento" e a "identidade” não têm a solidez de uma rocha, não são garantidos para toda vida, são bastante negociáveis e revogáveis, e de que as decisões que o próprio indivíduo toma, os caminhos que percorre, a maneira como age - e a determinação de se manter firme a tudo isso - são fatores cruciais tanto para o "pertencimento" quanto para a identidade “[...] a ideia de “ter uma identidade” não vai ocorrer às pessoas enquanto o "pertencimento” continuar a ter essa ideia na forma de uma tarefa a ser realizada, e realizada vezes e vezes sem conta, e não de uma só tacada. 
Para tanto esta mesma escola necessita trabalhar tanto a ideia de pertencimento quanto de identidade constantemente, como se entendesse que não se trata de algo definido, mas construído mediante o processo de aprendizagem. Seguindo o pensamento dos professores.

A segunda docente destacou que o Plano de Ação e o Projeto Político Pedagógico da escola precisam ser discutidos e repensados de acordo com o contexto intercultural real, não basta definir a existência da interculturalidade, é preciso inserir o aluno a escola, oportunizar situações de interação social e cultural. O educando precisa se sentir um sujeito historicamente representado, se perceber um ser diferente, partindo do princípio de que as diferenças é o que constrói a diversidade e as relações de contato com outras culturas.

Acredita-se que o aluno pode até estar inserido em um contexto urbano de escolarização, mas é retirado dele o direito de participar, atuar e interagir nos diversos momentos de propagação e/ou reflexão da própria cultura. Ainda com base nos relatos, é notório o processo de negação e exclusão dos povos étnicos enquanto “minorias”, em consequência da concepção de cultura numa perspectiva hierarquizada. Dentro deste contexto a entrevistada observou o fato do aluno indígena se caracterizar bilíngue, à medida que ele realiza leitura com a variante da sua língua materna, porém escreve sempre em língua portuguesa, esta situação reforça que a instituição de fato não promove o bilinguismo e não destaca a interculturalidade como objeto de aproximação entre as culturas e seus produtores.

No que concerne às dificuldades, a professora destaca a leitura, pois está dentro do processo de interação e exige uma comunicação oral com os demais. É um grande desafio para a instituição e seus professores. É um momento de reflexão e questionamento, mesmo contextualizando a diversidade cultural em suas aulas, o fato de grande parte dos alunos não falarem mais a sua língua materna é preocupante. A docente afirma que "Os alunos indígenas sentem-se envergonhados de se reconhecer devido às críticas, o desprezo e a desvalorização da sua cultura”. Ela continua afirmando que “A sociedade é preconceituosa, a construção no meio familiar é contaminada pela intolerância e pelo preconceito, originados nos meios midiáticos, sobretudo nas gerações que reproduzem a discriminação”. O relato da docente nos leva a uma reflexão acerca da entrevista realizada com Dietz, pela pesquisadora Araújo, no México:

Nossas sociedades sãs excludentes, nossas sociedades são discriminatórias, mas se desenvolvermos modelos educativos só para vítimas, então seguimos marginalizando, enquanto que os que marginalizam seguem sendo monolíngues, monoculturais (DIETZ/ARAÚJO, 2015, p. 323). 
A terceira professora destacou assim como os demais, que a língua é objeto cultural de referência para o processo de interação, então a partir da negação do direito de interagir é que concebemos a escola enquanto espaço de marginalização cultural. A docente relata que a instituição enquanto organização de ensino deve promover espaços de discussões e formular um Projeto Pedagógico que trabalhe com as diferenças em sala de aula de forma efetiva e democrática, pois somente assim teremos uma educação inclusiva, pensada e ofertada sobre a ótica das relações interculturais. Dando ênfase ao papel da escola enquanto Instituição Social e assim tem sua prática social, que segundo Severino:

Como prática social a educação se envolve de um tríplice modo com a sociabilidade: prepara os educandos para inserção na vida social; realiza-se em si mesma como exercício de sociabilidade; esse exercício é também conteúdo formativo. A educação depende da contribuição do conhecimento, sua atividade específica, também na crítica e superação das impregnações ideológicas. Sem essa vigilância crítica, a intervenção educacional se torna forte instrumento de dominação e de reprodução de relações sociais desumanizadoras (SEVERINO, 2001, p. 89).

Ressalta-se ainda que a escola aqui representada registra a presença de duas etnias evidentes em Roraima, a etnia Macuxi e a Wapixana. Todas as turmas da escola possuem alunos indígenas, mesmo sem muita liberdade para a autodefinição eles não são os únicos que compõem o grupo dos excluídos. Encontram-se nesses espaços outros povos que são excluídos por suas diferenças culturais e por não contemplar uma cultura elitizada.

A entrevistada profere que a inserção do aluno índio deveria ocorrer de forma natural, conforme papel da escola se a mesma estivesse preparada para recebê-lo, contudo alerta para o processo de relação cultural que em sua maioria é negado. Os discentes migram para a cidade em busca de melhorias, de acesso à educação e deparam-se em um espaço opressor, de discriminação e preconceito. A partir de então são obrigados a esquecer a sua língua, sua cultura, seus valores e a desconstrução da identidade é decretada,e eles devem adaptar-se a cultura do “contexto”, ou seja, dos não indígenas.

\section{CONSIDERAÇÕES}

É a partir do pensamento de superação da discriminação entre as diversidades culturais que compreendemos a escola como um espaço que reúne as diferenças étnicas, sociais, culturais e econômicas. Nessa perspectiva, a educação intercultural empenha-se com as relações entre os indivíduos culturalmente diferentes juntos aos outros. Trata-se de uma luta em busca de 
compreender a natureza, o contexto e os sentidos resultantes das relações entre as culturas. Diante disso,atentamos para o pensamento de Fleuri (2003, p. 31).

É sob esta perspectiva que a educação intercultural se preocupa com as relações entre os seres humanos culturalmente diferentes uns dos outros. Não apenas na busca de aprender o caráter de várias culturas, mas, sobretudo na busca de compreender os sentidos que suas ações assumem no contexto de seus respectivos padrões culturais e na disponibilidade de se deixar interpelar pelos sentidos de tais ações e pelos significados construídos por tais contextos.

Há uma concepção de que a diferença étnica ou cultural poderia fortalecer a desigualdade, tal pensamento caracteriza a insensibilidade às diversidades e promove a perda de características específicas de determinados grupos étnicos, como ocorre com a língua materna de nossos alunos indígenas que são inseridos em outro contexto de interação social onde a língua portuguesa é imposta, seja no processo de aquisição da escrita ou da linguagem oral, desconstruindo a identidade e descaracterizando a ideia de escola bilíngue, numa tentativa discriminada de homogeneização das culturas.

A intenção do estudo foi apresentar um entendimento diante da inserção do aluno indígena no contexto escolar urbano. A princípio é na escola que encontramos a concentração das diferenças; são as práticas, os valores, as crenças, as tradições, os símbolos representativos que constituem a identidade dos diferentes grupos sociais. Tal situação nos leva a distinção entre educação intercultural, educação escolar e interculturalidade. A instituição de ensino não pode conceber as diferenças culturais como um fenômeno isolado da educação escolar, entende-se que há interculturalidade, mas não há transformação das diferenças em um processo de interação, portanto, temos uma educação que do ponto de vista democrático não se define como intercultural em sua efetividade.

Nesse sentido, a inserção do indígena ainda consiste num verdadeiro desafio para a instituição, uma vez que o sujeito não se percebe incluso, sente-se envergonhado para se reconhecer devido às críticas, ao desprezo e a desvalorização da sua cultura, pois encontra-se em um ambiente onde as diferenças e a interação cultural são objetos de um pensamento hierarquizado, onde a cultura do não indígena sobressai, tal fato fica evidente quando analisamos o discurso dos professores, estes percebem a língua e a interação como um desafio que tende a reforçar a ideia de desigualdade cultural na escola em Boa Vista - Roraima.

O respeito às diferenças culturais, seria essencial para que os alunos, não apenas os indígenas se sentissem respeitados e seria um caminho a inclusão. Sabemos que seria necessário 
muito mais que isso para que sua inserção ocorra de forma efetiva, mas esse seria o segundo passo, considerando como primeiro passo o reconhecimento de que essas diferenças existem.

\section{REFERÊNCIAS}

BAUMAN, Zygmunt. Identidade entrevista a Benedetto Vecchi. Trad.: Carlos Alberto Medeiros. Rio de Janeiro: Zahar, 2005.

BRASIL. IBGE. Contagem da população 2010. Rio de Janeiro: IBGE, 2010.

. Ministério da Educação. Parâmetros Curriculares Nacionais. Temas Transversais. Brasília: MEC/2007.

. Secretaria de Educação Continuada, Alfabetização, Diversidade e Inclusão. Documento Final [da] I

Conferência Nacional de Educação Escolar Indígena/ Ministério da Educação, Secretaria de Educação Continuada, Alfabetização, Diversidade e Inclusão. Brasília: SECADI, 2014.

MEC. II Conferência Nacional de Educação Escolar Indígena: documento - referência/[elaborado pela] Comissão Organizadora Nacional. Brasília: Ministério da Educação, Secretaria de Educação Continuada, Alfabetização, Diversidade e Inclusão, Secadi, 2016.

MEC. Lei de Diretrizes e Bases da Educação Nacional, no 9394/1996. Brasília: 1996.

CANDAU, Vera Maria Ferrão. Educação Intercultural no contexto brasileiro: questões e desafios. Rio de Janeiro: PUC - Rio; Novamerica, 2003.

DIETZ, Gunther. ; ARAÚJO, Daniele. Entrevista com Gunther Dietz. Espaço Ameríndio, Porto Alegre, v. 9, n. 3, p. 320-325, 2015.

FLEURI, Reinaldo Matias. Intercultura e educação. Revista Brasileira de Educação, Rio de Janeiro, 2003.

Reinaldo Matias. Educação intercultural: a construção da identidade e da diferença nos movimentos sociais. Revista Perspectiva, Florianópolis, 2002.

GEERTZ, Cliford. A interpretação das Culturas. Rio de Janeiro: LTC, 2008.

OLIVEIRA, C. R. Identidade étnica, reconhecimento e o mundo moral. Revista ANTHROPOLÓGICAS, UFPE, v. 16, n. 2, p. 9-40, 2005.

SASSAKI, Romeu Kazumi. Inclusão./Construindo uma sociedade para todos. Rio de Janeiro: WVA, Edição 2006.

SEVERINO, Antônio Joaquim. Metodologia do Trabalho Científico. 23. ed. São Paulo: Cortez, 2007. . Antônio Joaquim. Educação, sujeito e história. São Paulo: Olho d’ Água, 2001.

YIN, Robert K. Estudo de caso - planejamento e métodos. 2. ed. Porto Alegre: Bookman, 2001. 


\section{RESUMO}

O trabalho em questão é resultado de um estudo de caso realizado em uma Escola Municipal situada na capital de Boa Vista. A inserção do aluno indígena dentro do processo de escolarização urbano consiste em um verdadeiro desafio, pois abre uma discussão envolvendo as políticas públicas que regulamentam a educação numa perspectiva ótica da inclusão, a valorização da cultura indígena nos diversos contextos de interação social, o papel da escola enquanto instituição seja na recepção, no atendimento, sobretudo na oferta do ensino de forma igualitária. O objetivo da pesquisa foi conhecer como ocorre o processo de inserção do aluno indígena na educação escolar no contexto urbano de Boa Vista - RR. Com uma abordagem qualitativa, a investigação constituiu de pesquisa bibliográfica, análise documental e a utilização da técnica de entrevista, esta realizada com três coordenadores pedagógicos e três professores do Ensino Fundamental I. A referida escola apresenta o maior número de alunos regularmente matriculados segundo dados da Secretaria Municipal de Educação e tem a maior concentração alunos indígenas em uma escola urbana do $r$ 'nicípio. Dentro desta perspectiva a pesquisa apresentou a compreensão do papel da escola no processo de iserção do aluno indígena, da participação e da interação deste no que diz respeito às diferenças culturais e o reconhecimento da interculturalidade enquanto objeto de aproximação entre as culturas e os seus produtores.

Palavras-chave: Educação. Interculturalidade. Aluno indígena.

\section{SCHOOL EDUCATION AND INTERCULTURALITY: THE INDIGENOUS STUDENTS INSERTION IN THE URBAN CONTEXT IN BOA VISTA - RR}

\section{ABSTRACT}

The following article is the result of a case study made in a Municipal School located in Boa Vista. The insertion of the Indian Student in the process of urban education consists in a real challenge, because it opens a discussion about public policy that regulate education under the inclusion's perspective, the valuation of the indigenous culture in the various contexts of social interaction, the school's role as institution whether in the reception, attending, or specially in the equal offer of teaching. The research's purpose was to know how occurs the insertion process of the indian student in the urban education context of Boa Vista - RR. With a qualitative approach, the investigation used literature search, document review and interviews with three pedagogical coordinators and three professors from a elementary school I. The said school presents the highest number of students regularly registered according to data from Municipal Education Department, and it has the largest concentration of Indian students in an urban school from the city. From that point of view, the work will give a comprehension of the school's role in the insertion process from the Indian students, of the participation and interaction from what is related to the cultural differences and the recognising of the interculturality as a mechanism of approximation between the cultures and their producers.

Keywords: Education. Interculturality. Indian Student.

\section{EDUCACIÓN ESCOLAR E INTERCULTURALIDAD: LA INSERCIÓN DEL ALUMNO INDÍGENA EN LA CONTEXTUALIZACIÓN URBANA EN BOA VISTA-RR}

\section{RESUMEN}

El trabajo en cuestión es el resultado de un estudio de caso realizado en una Escuela Municipal ubicada en la capital Boa Vista. La inserción del alumno indígena dentro del proceso de escolarización urbana , consiste en un real desafío , pues, conlleva a la discusión involucrando las políticas públicas que rigen la educación en una perspectiva óptica de la inclusión, la valoración de la cultura indígena en las diversas contextualizaciones de interacción social , la función de la escuela mientras institución sea en la recepción, en el atendimiento, sobretodo en la manera de ofrecimiento de una enseñanza igualitaria. El propósito de esta investigación es conocer cómo se ocurre el proceso de inserción del alumno indígena en la educación escolar en la contextualización urbana de Boa Vista-RR. Con un aporte cualitativo, la investigación consiste en una revisión bibliográfica, y análisis documental y la utilización de técnica de encuesta. La investigación fue realizada con tres coordinadores pedagógicos y tres profesores de educación elementar años iniciales. La referida escuela presenta el más grande número de alumnos regularmente matriculados según información de la Secretaria 
Municipal de Educación, se concentra de igual modo el más grande número de alumno indígena en una escuela urbana del municipio. Dentro de esta perspectiva, este trabajo traerá una comprensión de la función de la escuela en el proceso de inserción del alumno indígena, de la participación y de la interacción de este en lo que se refiere a las diferencias culturales y el reconocimiento de la interculturalidad mientras obyecto de aproximación entre las culturas y los que las producen.

Palabras clave: Educación. Interculturalidad. Alumno indígena. 